\title{
Vardiyalı Çalışan Kadın Hemşirelerde Rol-Aktivite Dengesi ve Yaşam Kalitesi Arasındaki İlişkinin İncelenmesi
}

Investigation of the Relationship between Occupational Balance and Quality of Life in ShiftWorking Female Nurses

\section{Gamze EKICi' ${ }^{1}$, Merve DEMIRBAŞ ${ }^{2}$}

${ }_{1}^{1}$ Prof. Dr., Hacettepe Üniversitesi, Sağlık Bilimleri Fakültesi, Ergoterapi Bölümü, Ankara, Türkiye

${ }^{2}$ Erg., Hacettepe Üniversitesi, Sağlık Bilimleri Fakültesi, Ergoterapi Bölümü, Ankara, Türkiye

\section{öz}

\begin{abstract}
Amaç: Hemşirelik, yoğun iş yükü altında çalışmayı gerektirmektedir. Buna vardiyalı çalışma ve kadınlar açısından ailevi sorumluluklar da eklendiğinde yükün arttığı bilinmektedir. Bu çalışma vardiyalı çalışan kadın hemşirelerde rol-aktivite dengesi ve yaşam kalitesi arasındaki ilişkiyi incelemek amacıyla yapıldı. Gereç ve Yöntem: Çalışmaya vardiyalı çalışan 73 kadın hemşire dâhil edildi. Katılımcılara Rol-Aktivite Dengesi Anketi (RADA) ve yaşam kalitesini değerlendirmek amacıyla Nottingham Sağlık Profili (NSP) uygulandı. Sonuçlar: Çalışmaya katılan vardiyalı çalışan kadın hemşirelerin RADA sonuçları ile ve NSP alt parametreleri ve toplam puanı arasında anlamlı bir ilişki olduğu ( $r=0.638, p=0.001)$ bulundu. Tartışma: Kadın hemşirelerin, rol-aktivite dengelerinin orta düzeyin üzerinde bozuk olduğu, yaşam kalitelerinin ise orta düzeyin altında olumsuz etkilendiği görülmektedir. Bireyin fiziksel aktivite ve enerji düzeyi, uyku kalitesi, ağrı bulguları, ruhsal ve sosyal durumu gibi sağlığıyla ilişkili parametrelerin etkilenmiş olması üzerinde durulması gereken önemli sorunlardır. Hemşirelerin rol-aktivite dengesinin düzenlenmesi bütün bu sorunların düzeltilebilmesi ile ilişkili bulunmuştur. Bu nedenle, rol-aktivite dengesi açısından vardiyalı çalışan kadın hemşirelerin tamamının değerlendirilmesi ve bu hemşirelerin sağlığını koruyabilmesi için vardiyalı çalışma sıklığının ve izin zamanlarının düzenlenmesi; serbest zaman, üretkenlik ve kendine bakım alanlarında anlamlı ve amaçlı aktivitelerin oluşturulması gibi önlemlerin alınması değerli olacaktır.
\end{abstract}

Anahtar Kelimeler: Kadın; Hemşirelik; Vardiyalı-çalışma; Yaşam kalitesi

\section{ABSTRACT}

Purpose: Nursing requires working under intensive workload. It is known that the burden increases when family responsibility and shifts are added. The aim of this study was to investigate the relationship between occupational balance and quality of life in shift-working female nurses. Material and Methods: Seventy-three female nurses working in shifts were included in the study. An Occupational Balance Questionnaire(OBQ) and Nottingham Health Profile (NHP) were applied to assess quality of life. Results: Significant correlations were found among RADA results, and NHP sub-parameters and total score of female nurses working in shifts $(r=0.638, p=0.001)$. Discussion: Occupational balance of female nurses was impaired above the moderate level and quality of life was negatively affected below the intermediate level. Physical activity and energy level, sleep quality, pain symptoms, and mental and social status of the individual are important problems that need to be focused on. Regulating the occupational balance of nurses was correlated with the improving of all these problems. Therefore, in terms of the occupational balance, it will be valuable to evaluate all shift-working nurses, to regulate shifting frequency and off times of these nurses to protect their health and to take precautions such as the creation of meaningful and purposeful activities in the areas of leisure time, productivity and self-care.

Keywords: Female; Nursing; Shift-Work; Quality of life 
Vardiyalı çalışma, bir hafta veya bir ay boyunca farklı sabit dönemlerde rotasyonu içeren bir çalışma şeklidir. Vardiyalı olarak çalışan kişilerde, düzenli günlük çalışma ve sosyal yaşamın dışına çıkılmasından ve uyku-uyanıklık döngüsündeki bozulmadan dolayı pek çok ruhsal ve fiziksel sorunlar ortaya çıkabilmektedir (Selvi, Özdemir, Özdemir ve ark, 2010). Sağılı çalışanlarının, normal çalışma saatleri ve günleri dışında, yoğun iş yükü altında çalışmak durumunda kalmaktadır. Ayrıca yaşamsal tehdidi bulunan insanlarla çalışması, aile ve hastaların büyük beklentileri ile karşılaşması, iş yerinde çalışan diğer personelle ilişki ve görev paylaşımı gibi sorunların yaşanması, uyku düzeninin bozulması ve oluşabilecek ekonomik sorunların varlığı, iş ile ilgili stres ve gerginliğe yol açmaktadır. Hemşireler, hastalarla en uzun süre birlikte olan sağlık profesyonelleri olup, hasta bireyin ve ailesinin her türlü sorununda ilk başvurduğu ve ekip içerisinde iletişimi sağlayarak anahtar rol oynayan sağlık personelidir. Yoğun stres altında çalışma, hemşireleri ruhsal olarak etkileyebilmekte ve bu durum yaşam kalitelerine olumsuz yansıyabilmektedir (Kaçmaz, 2011; French, Lenton, Walters ve ark, 2000; Yıldırım ve Hacıhasanoğlu, 2011). Normal çalışma yaşamı yani gündüz çalışma düzeni, hem toplumun diğer bireyleriyle eğitim, toplu eğlence ve dinlenme olanaklarını hem de biyolojik saat düzenini olumsuz etkilemektedir. Vardiyalı çalışma sistemi her iki alanın saatleriyle çatışmaktadır. Biyolojik saat düzeniyle olan çatışma, bireyi fizyolojik açıdan etkilerken; toplumsal saat düzenindeki çatışma, bireyde psikososyal yönden sorunlara neden olabilmektedir (Ursavaş ve Ege, 2004; Nicholson ve D'Auriat, 1999).

Türk Hemşireler Derneğinin, hemşirelerde vardiyalı çalışma sistemi ile ilgili hazırladığı raporda, hem gece hem de gündüz değişen saatlerde uzun sürelerde çalışmanın hemşirelerin kendi biyolojik ritimlerini, aile ve sosyal yaşantısını, çalışma hayatında bakımını verdiği hastaların güvenliğini ve hasta bakımını etkilediğini bildirmektedir (THD, 2008). Benzer şekilde Uluslararası Çalışma Örgütü, vardiyalı ve gece gündüz değişen şekilde çalışma sisteminin hemşirelerde çalışma ortamı kaynaklı başlıca stresörlerden biri olarak tanımlamaktadır (ILO, 2016). Vardiyalı ve gece gündüz değişen şekilde çalışma nedeniyle yaşamdaki rutin aktivitelere katılamamak, toplumsal ve sosyal rollerini yerine getirememek, mesleki tatminde azalmaya yol açabildiği gibi sorunlar dolayısıyla bireyin tüm yaşamını etkileyebilir. Hemşirelerle yapılan çalışmalarda, vardiyalı ve gece gündüz değişen şekilde çalışmanın sosyal faaliyetleri azalttığı, strese neden olduğu ve stresle baş etme becerilerini azalttığı bildirilmektedir (DeMoss, Mcgrail, Haus ve ark, 2004; Selvi ve ark, 2010).

Kadın hemşirelerin bu denli yoğun çalışma yaşamlarına ek olarak, ev ve özel hayatları ve buradan önemli annelik, eş olma gibi rolleri vardır. Bu rollerin yoğun çalışma hayatı nedeniyle olumsuz etkilenebileceği düşünülmektedir. Rollerini gerçekleştirirken bir arada olduğu diğer kişilerle iletişimleri azaldığı için sosyal izolasyon yaşayabilmektedirler. Vardiyalı çalışma sistemiyle çalışanlar kendilerini ailelerinden ve arkadaş çevrelerinden dışlanmış hissetmekte, sosyal ve aile içi rollerini yerine getirmekte güçlük yaşamaktadırlar. Aynı zamanda, bu kişiler ailenin bir üyesi ve bir çalışan olarak var olan rollerinde, rol-aktivite talepleri ve gereklilikler arasında zorlanma, zaman konusunda sıkıntılar yaşama ve rol-aktivite performansında yetersiz hissetme gibi duyguları yaşayabilmektedir (Wilson, 2002). Yaşam kalitesi bireyin fiziksel işlevlerini, ruhsal durumunu, aile içindeki ve dışındaki toplumsal ilişkilerini ve rollerini kapsar. Ayrıca, bireyin işlevselliğinin ne düzeyde olduğunu gösterir (Testa ve Simonson, 1996; Yıldırım ve ark, 2011).

Rol - aktivite dengesi, bireylerin hayatını oluşturan üç ana aktivite (iş - üretici, kendine bakım ve serbest zaman) alanlarındaki performanslarını, memnuniyet ve katılımlarını içermektedir. Rol-aktivitenin karakteristik özellikleri ve rol-aktiviteler arasında dengenin oluşturulması; benlik algısı ve iyi olma haliyle ilişkilidir. Rol - aktivite dengesi aktivitenin nasıl olduğu ve rolaktivite performansı ile ilişkilidir. Ayrıca, iş-yaşam dengesini de kapsamaktadır (Matuska ve Christiansen, 2008; Anaby, Backman ve Jarus, 2010).

Yaptığımız literatür taramasına göre sağlık çalışanlarında yaşam kalitesi ve rol- aktivite dengesinin incelendiği ve bunların birbiriyle olan ilişkisine yönelik herhangi bir çalışmaya rastlanılmamıştır. Aynı zamanda, yaşam kalitesi ve etkileyen değişkenlerle ilgili sınırlı sayıda çalışma olduğu gözlemlenmiştir (Selvi ve ark, 2010; Wilson, 2002; Matuska ve ark, 2008; Anaby ve ark, 2010). Hâlbuki vardiyalı sağlık çalışanlarının sağlık ve iyilik hali için bireyin hayatını oluşturan rol aktivite dengesinin incelenmesi önemlidir (Selvi ve ark, 2010; Yeşilçiçek Çalık, Aktaş, Kobya Bulut ve ark, 2015). Biz bu nedenle vardiyalı çalışan kadın hemşirelerde rol - aktivite dengesi ve yaşam kalitesi arasındaki ilişkiyi incelemek amacıyla bu çalışmayı planladık. 


\section{GEREÇ VE YÖNTEM}

Çalışmamız Eylül 2018-Haziran 2019 tarih aralığında Ankara, İstanbul ve Kocaeli illerinde yapılmıştır. Çalışma için 69 vakanın dahil edildiği Özel Ankara Güven Hastanesinden bilimsel araştırma izni alınmıştır. İstanbul ve Kocaeli'nden11 kadın hemşire gönüllük ilkesi dahilinde birebir görüşülerek değerlendirmeye alınmıştır. Çalışma kapsamında son altı aydır ayda en az 4 adet nöbet tutan 80 kadın hemşire ile görüşme yapılmış olup, 7'sinin değerlendirmeleri tamamlayamamaları nedeni ile yaş ortalaması $29,10 \pm 5,19$ yıl olan 73 kişi ile çalışma tamamlanmıştır. Çalışma öncesinde katılımcılara çalışmanın amacı anlatılmıştır ve her katılımcıya Helsinki deklarasyon prensiplerine uygun olarak bilgilendirilmiş onam formu imzalatılmıştır.

Katılımcı sosyo-demografik bilgileri; Araştırmaya katılan vardiyalı çalışan hemşirelerin yaş, boy, vücut ağırlığı, vücut kütle indeksi, eğitim durumu, medeni durumu, sigara/alkol kullanımı yaşadığı, ev kaldığı ev ve yaşama ortamları sorgulayan sorulardan oluşmaktadır.

Rol-Aktivite Dengesi Anketi (RADA); Christiansen ve Wagman aktivite-rol dengesinin kullanıma hazır ve tutarlı ölçülebilen bir ölçeğinin olmamasının sınırlayıcı bir faktör olduğunu düşünmüşler (Christiansen, 1996; Wagman, Håkansson ve Björklund, 2012). Bunun gibi limitasyonlar dikkate alınarak RADA geliştirmişlerdir (Dür, Steiner, Fialka-Moser ve ark 2014). RADA günlük yaşantımızda yer alan işüretici, kendine bakım, serbest zaman gibi aktivitelerin bireyi ve rollerini nasıl etkilediğini sorgulayan bir testtir. Toplam 10 sorudan oluşmakta, her soru 3 seçenek ve her seçenek sırayla 1, 2, 3 puandır ve puanlama en az 10 en çok 30 puan aralığında yapılmaktadır. Bu anketin Türkçe 'ye uyarlanmasında anadili Türkçe olan, iyi derece İngilizce bilen ve konusunda uzman, geri çevirisinde ise iki yeminli tercüman görev almıştır. Anket bu aşamalar dikkate alınarak sadece Türkçe'ye çevrilerek kullanılmıştır.

Nottingham Sağlık Profili (NSP); 1985 yılında Hunt ve arkadaşları tarafından geliştirilmiştir. Orijinali İngilizce olup birçok dile çevrilmiştir. Sağlıkla ilgili yaşam kalitesini değerlendirmek için
Türkçe geçerliliği Küçükdeveci ve ark. tarafından yapılan NSP' nin Türkçe versiyonu kullanılmıştır. NSP, kişinin algıladığı sağlık problemlerini ve bu problemlerin normal günlük aktiviteleri etkileme düzeyini ölçen bir genel yaşam kalitesi anketidir. Anket, 38 maddeden oluşur ve sağlık statüsü ile ilgili altı boyutu değerlendirir: Enerji (3 madde), ağrı (8 madde), emosyonel reaksiyonlar (9 madde), uyku (5 madde), sosyal izolasyon (5 madde) ve fiziksel aktivite ( 8 madde). Sorulara evet veya hayır seklinde cevap verilir. Her bir bölüme 0-100 arası puanlama yapılır. 0 en iyi sağlık durumunu, 100 en kötü sağlık durumunu gösterir. Çalışma kapsamında NSP'nin alt skorları ve toplam NHP puanı değerlendirilmiştir. Toplam NSP puanı alt skorların toplamından elde edilmiştir. NSP parametrelerinin cronbach's alpha katsayıları 0,56 ve 0,83 arsında değişmektedir (Küçükdeveci, McKenna, Kutlay ve ark, 2010).

\section{Istatistiksel Analiz}

Çalışmada elde edilen verilerin analizinde SPSS 22 istatistik programı kullanıldı. Katılımcıların eğitim, medeni durum, yaşadığı- kaldığı ev, yaşadığı ortam, alkol-sigara kullanımı gibi nitel veriler frekans değerleri hesaplandı. Veriler ile ilgili sayı ve yüzdelik dilimler tanımlandı. Yaş, boy, kilo, vücut kütle endeksi, çalışma yılı nicel verileri ortalama \pm standart sapma değerleri hesaplandı. Rol-aktivite dengesi ve yaşam kalitesi arasındaki ilişki Spearman korelasyon analizi testi ile yapıldı. $p<0,05$ anlamlılık değeri olarak kabul edildi.

\section{SONUÇLAR}

Yetmiş üç vardiyalı çalışan kadın hemşire ile tamamlanan çalışmada yapılan istatistiksel analiz sonuçlarına göre çalışmaya katılan vardiyalı çalışan kadın hemşirelerin \%50,7'sinin medeni durumunun bekâr ( $n=37)$, \%67,1'inin eğitim durumunun üniversite $(n=49), \% 54,8$ 'inin alkol kullanımının olmadığı $(n=40)$, $\% 56,2$ 'sinin sigara kullanımının olmadığı $(n=41)$, $\% 97,3$ 'ünün apartman dairesinde yaşadığı $(n=71)$, $\% 46,6$ 'sının kaldığı evin kendisine ait olduğu $(n=34)$, \%35,6'sının eşi ve çocuklarıyla birlikte yaşadığı $(n=26)$ tespit edilmiştir. Ayrıca katılımcıların boy ortalamasının $1,65 \pm 3,94 \mathrm{~m}$, kilo ortalamalarının $62,14 \pm 7,84 \mathrm{~kg}$, vücut kütle indekslerinin $22,70 \pm 2,93 \mathrm{~kg} / \mathrm{m}^{2}$, çalışma yılı ortalamalarının $8,16 \pm 5,89$ yıl ortalama ve standart sapma değerleri olduğu tespit edilmiş olup yaşla birlikte bu bulgular Tablo 1'de verilmiştir. 
Tablo 1. Katılımcıların sosyo-demografik özellikleri $(n=73$ )

\begin{tabular}{|c|c|c|}
\hline & $\mathbf{n}$ & $\%$ \\
\hline \multicolumn{3}{|l|}{ Medeni durum } \\
\hline Evli & 35 & 47,9 \\
\hline Bekar & 37 & 50,7 \\
\hline Boşanmış & 1 & 1,4 \\
\hline \multicolumn{3}{|l|}{ Eğitim } \\
\hline Lise & 24 & 32,9 \\
\hline Üniversite & 49 & 67,1 \\
\hline \multicolumn{3}{|l|}{ Alkol } \\
\hline Yok & 40 & 54,8 \\
\hline Nadiren & 2 & 38,4 \\
\hline Haftada 1 gün & 4 & 5,5 \\
\hline Hergün & 1 & 1,4 \\
\hline \multicolumn{3}{|l|}{ Sigara } \\
\hline Yok & 41 & 56,2 \\
\hline Bırakmış & 4 & 5,5 \\
\hline Nadiren & 5 & 6,8 \\
\hline Haftada 1 paket & 5 & 6,8 \\
\hline Günde 1 paket & 18 & 24,7 \\
\hline \multicolumn{3}{|l|}{ Yaşadığı ev } \\
\hline Apartman dairesi & 71 & 97,3 \\
\hline Müstakil & 2 & 2,7 \\
\hline \multicolumn{3}{|l|}{ Kaldığı ev } \\
\hline Kendisine ait & 34 & 46,6 \\
\hline Ailesine ait & 7 & 9,6 \\
\hline Kira & 31 & 42,5 \\
\hline Arkadaşına ait & 1 & 1,4 \\
\hline \multicolumn{3}{|l|}{ Yaşadığı ortamı } \\
\hline Tek başına & 17 & 23,3 \\
\hline Eşiyle & 10 & 13,7 \\
\hline Eşi ve çocuklarıyla & 6 & 35,6 \\
\hline Ailesiyle & 9 & 12,3 \\
\hline \multirow[t]{2}{*}{ Arkadaşlarıyla } & 11 & 15,1 \\
\hline & \multicolumn{2}{|r|}{$\bar{X} \pm$ SS } \\
\hline Yaş (yıl) & \multicolumn{2}{|r|}{$29,10 \pm 5,19$} \\
\hline Boy (m) & \multicolumn{2}{|r|}{$1,65 \pm 3,94$} \\
\hline Kilo (kg) & \multicolumn{2}{|r|}{$62,14 \pm 7,84$} \\
\hline Vücut kütle indeksi $\left(\mathrm{kg} / \mathrm{m}^{2}\right)$ & \multicolumn{2}{|r|}{$22,70 \pm 2,93$} \\
\hline Çalışma yılı & \multicolumn{2}{|r|}{$8,16 \pm 5,89$} \\
\hline
\end{tabular}


RADA ve NSP değerlerinin bir kesme puanı olmamakla birlikte Tablo 2'de görüldüğü üzere alınabilecek puanlar açısından her iki ankette de maksimum puanlar ikiye bölündüğünde bu seviye orta düzey olarak dikkate alınırsa; orta düzeyin altı hafif, üstü ise şiddetli olarak düşünülmüştür. Buna göre katılımcıların rol-aktivite dengelerinin maksimum 30 puan üzerinde düşünüldüğünde 21 puanla ortalamanın üzerinde bozuk olduğu görülmüştür. Ayrıca, NSP alt parametreleri ayrı ayrı 100 puan, toplamda ise 600 puan üzerinden değerlendirildiğinde ortalama puanların düşük olması ölçeğin doğası nedeniyle iyiye daha yaklaştığını bize gösterirken, bireylerin yaşam kalitesinin hafif düzeyde olumsuz yönde etkilendiği bulunmuştur. Ayrıca, yaşam kalitesinin tüm parametreleri ile bireyin rol-aktivite dengesi arasında ilişki Tablo 3'te gösterilmiştir.

Tablo 2. Rol-Aktivite Dengesi ve Yaşam Kalitesi ortalama değerleri $(n=73)$

\section{$\bar{X} \pm$ SS}

Rol-Aktivite Dengesi Anketi (RADA) (0-30)

$21,25 \pm 3,13$

Nottingham Sağlık Profili (NSP)

\begin{tabular}{ll}
\hline NSP-Enerji (0-100) & $49,50 \pm 42,01$ \\
\hline NSP-Ağrı (0-100) & $24,02 \pm 25,34$ \\
\hline NSP-Duygusal Reaksiyonlar (0-100) & $32,27 \pm 30,35$ \\
\hline NSP-Sosyal İzolasyon (0-100) & $20,18 \pm 28,05$ \\
\hline NSP-Uyku (0-100) & $32,45 \pm 32,52$ \\
\hline NSP-Fiziksel Aktivite (0-100) & $16,25 \pm 20,00$ \\
\hline NSP-Toplam (0-600) & $174,60 \pm 129,47$
\end{tabular}

Tablo 3. Rol-Aktivite Dengesi ile Yaşam Kalitesi arasındaki ilişki $(n=73)$

\begin{tabular}{llllllll}
\hline NSP & $\begin{array}{l}\text { NSP- } \\
\text { Enerji }\end{array}$ & NSP-Ağrı & $\begin{array}{l}\text { NSP- } \\
\text { Duygusal } \\
\text { reaksiyonlar }\end{array}$ & $\begin{array}{l}\text { NSP- } \\
\text { Sosyal } \\
\text { izolasyon }\end{array}$ & $\begin{array}{l}\text { NSP- } \\
\text { Uyku }\end{array}$ & $\begin{array}{l}\text { NSP- } \\
\text { Fiziksel } \\
\text { aktivite }\end{array}$ & $\begin{array}{l}\text { NSP- } \\
\text { Toplam }\end{array}$ \\
\hline RADA & $r=0,413$ & $r=0,461$ & $r=0,564$ & $r=0,567$ & $r=0,443$ & $r=0,345$ & $r=0,638$ \\
\hline & $p=0,001^{*}$ & $p=0,001^{*}$ & $p=0,001^{*}$ & $p=0,001^{*}$ & $p=0,001^{*}$ & $p=0,003^{*}$ & $p=0,001^{*}$ \\
\hline
\end{tabular}

(NSP: Nottingham sağlık profili / RADA: Rol- aktivite dengesi anketi ${ }^{*} p<0,05$ )

\section{TARTIŞMA}

Vardiyalı çalışan kadın hemşirelerde yaşam kalitesi ve rol-aktivite dengesi arasındaki ilişkiyi incelemek amacıyla yaptığımı çalışmada sağlıkla ilişkili yaşam kalitesinin tüm parametreleri ile rol-aktivite dengesi arasında ilişki bulunmuştur. Hemşireler yaşamları boyunca, vardiyalı ve nöbetli çalışma sisteminin getirdiği güçlüklerle baş etmek durumunda kalmıştır. $\mathrm{Bu}$ durumun yaptığımız inceleme sonucu katılımcıların yaşam kalitesini olumsuz yönde etkilediği, rol-aktivite dengesinde ise bozukluk olduğu görülmüştür.

Vardiyalı çalışan hemşireler üzerine yapılan bir çalışmada, çalışmaya katılan hemşirelerin çoğunda halsizlik ve yorgunluk yakınmaları olduğunu ve çalışma şeklinin yüksek oranda yorgunluğa yol açtığı tespit edilmiş (Ergüney, Tan, Sivrikaya ve ark, 2001). Aynı zamanda, farklı bir çalışmada da, vardiyalı çalışmanın ve gece vardiyasının etkilerinin ertesi gün de yorgunluğa neden olduğunu belirtilmiştir (Zverev ve Misiri, 2009). Çalışmamızda da katılımcıların rolaktivite dengesi bozuldukça, yaşam kalitesini 
değerlendirmek için kullandığımız, NSP'nin alt parametresi olan enerji parametresinde hafif düzeyde etkilenim olduğu tespit edildi. Yani vardiyalı çalışan hemşirelerde rol-aktivite dengesi bozuldukça, bireyin enerjisinin azaldığı ve yorgunluk belirtilerinin ortaya çıktığı görülmektedir.

Çalışmamızla benzer şekilde, vardiyalı çalışan hemşirelerde ağrıyı değerlendiren bir araştırmada, gece çalışan bireylerde, baş ve sırt ağrısı gibi somatik belirtilerin kronik yorgunluk şikâyetlerine eşlik ettiği ve bu durumun da fiziksel yetersizliklere yol açtığı tespit edilmiştir (Samaha, Lal, Samaha ve ark, 2007). Başka bir çalışmada da, katılan hemşirelerin çoğunda eklem ve bacak ağrıları olduğu tespit edilmiştir (Ergüney ve ark, 2001). Çalışmamızda da, ağrı parametresinde hafif etkilenim tespit edilmiş olup, hemşirelerde rol-aktivite dengesi bozuldukça ağrılarının da arttığı görülmüştür.

Yaşam kalitesi bireyin algısıyla ve içinde bulunduğu hem ruhsal hem de fiziksel durumlarla oldukça ilişkilidir. Özellikle "duygusal reaksiyonlar" ve "sosyal izolasyon" gibi parametreler açısından bakıldığında yapılan bir çalışmada vardiyalı olarak çalışanlarda çeşitli psikosomatik ve psikonörotik şikâyetlerin daha yaygın olduğu ve bir takım ruhsal rahatsızlıkların ve sosyal sorunların ortaya çıktığı bildirilmiştir (Pati, Chandrawshi ve Reinberg, 2002). Vardiyalı olarak çalışanlar daha stresli çalışma koşulları, aile ve sosyal yaşamdaki zorluklarla bağlantılı olarak sıklıkla sinirlilik ve kaygıdan şikâyet ederler. Anksiyete düzeyinde yüksekliğin de eşlik ettiği bireylerde, stresle baş etme becerisinde azalma ve psikolojik sorunlarla baş etme becerilerinin kaybolduğu görülmüştür. Ruhsal sorunların altında yatan mekanizmanın, sirkadiyen ritimde uyum problemi ve psikososyal stres olduğu düşünülmüştür. Vardiyalı olarak çalışanlarda görülen ruhsal rahatsızlıklar arasında depresif bozukluklar ve anksiyete bozuklukları, uyku sorunları, alkol ve ilaç bağımlılıkları sayılabileceği tespit edilmiştir. (Cole, Loving ve Kripke, 1990; Sarıcaoğlu, Akıncı, Gözaçan ve ark, 2005; Selvi ve ark, 2010).

Vardiyalı ve nöbetli çalışmanın önemli sonuçlarından biri değişen saatlerdeki çalışma düzeninin aile ve sosyal ilişkiler üzerine olan etkileridir. Bu şekilde çalışan bireyler, rollerini gerçekleştirirken bir arada olduğu diğer kişilerle iletişimleri azaldığı için sosyal izolasyon yaşayabilmektedirler. Vardiyalı çalışma sistemiyle çalışanlar kendilerini ailelerinden ve arkadaş çevrelerinden dışlanmış hissedebilmekte, sosyal ve aile içi rollerini yerine getirmekte güçlük yaşamaktadırlar. Aynı zamanda bu kişiler, ailenin bir üyesi ve bir çalışan olarak var olan rollerinde, rolaktivite talepleri ve gereklilikler arasında zorlanma, zaman konusunda sıkıntılar yaşama ve rol-aktivite performansında yetersiz hissetme gibi duyguları yaşayabilmektedir ( Wilson, 2002; DeMoss ve ark., 2004; THD,2008). Sosyal yaşam ve aile ile ilgili aktivitelerin çoğu akşam saatlerinde veya hafta sonlarında düzenlendiğinden sosyal içerikli eğlence ve kültürel etkinliklere katılmaları veya arkadaş ilişkileri kurmaları güçleşmektedir. Ayrıca, vardiyalı çalışanların çocukları ile geçirilebilecek zamanın kısıtlılığı, çocukların bakımı ile ilgilenememek, eş ile iletişimde sorunların artması, vardiyalı çalışanların aile yaşantısına ilişkin ortak sorunlarından bazılarıdır (THD,2008). Vardiyalı çalışan işçiler üzerine yapılan başka bir çalışmada ise çalışma saatleri nedeni ile işçilerin sosyal yaşantılarının, eşi ve çocuklarıyla olan ilişkilerinin sık sık ya da sürekli etkilendiğini belirtmiştir (Gedikli, 2008). Türk hemşireler derneğinin yaptığı bir çalışmada ise vardiyalı çalışan hemşirelerin çalışma saatlerinin sosyal yaşamları üzerine etkileri şu şekilde saptanmış; Çocuklarına vakit ayıramama, kaliteli zaman ayıramama, bebek/çocuk bakımında zorlanma, çocuğun sosyalizasyon gereksinimlerini karşılayamama, rol-aktivitelerini yerine getirememe, rollerinde yetersizlik (annelik, eş, evlat, komşuluk) duygusu, roller arasında çatışma, evin bakımı ve düzenini sürdürmede eksiklik, eş ve ailelerle ilişkileri düzenleyememe, ilişkilerde bozulma, aileyle ve yakın çevreyle sosyal yaşamını düzenleyememe (değişken çalışma saatleri), akraba ilişkilerinde kısıtlanma, komşularla iletişimin bozulması, sosyal izolasyon, grup aktivitelerinin dışında kalma, yalnızlaşma, sosyal ayrışma, sosyal aktivitelerden keyif alamama İnsanlarla tanışma, paylaşma ve sosyal olanakların sınırlılığı, hayatını planlayamama ve kontrol kaybı, serbest zaman aktivitelerini planlayamama, kültürel faaliyetlerden yoksunluk, hobilerini yerine getirememe (terk etme), kişisel gelişim olanaklarından kısıtlanma, iş yerinde nöbet ayarlamaları yüzünden ekip arkadaşları ile çatışma (THD, 2008). Bir başka çalışmada elde edilen veriler sonucu vardiyalı çalışan hemşirelerin sosyal hayatlarını olumsuz yönde etkileyen diğer bir konunun, bayram ve hafta sonu tatili gibi özel günlerde çalışmak durumunda kalmaları olduğu belirtilmiştir (Ruggiero, 2003). Biz de çalışmamızda bu verilere benzer olarak rol-aktivite dengesinde bozukluk arttıkça, yaşam kalitesini belirlemek amacıyla kullandığımız Nottingham sağlık 
profilinin alt parametresi olan sosyal izolasyon parametresinde olumsuz yönde hafif etkilenme olduğunu tespit ettik.

Hemşirelerde uyku problemleri üzerine yapılan bazı çalışmalarda, çalışmaya katılan hemşirelerin yarısından çoğunun uykusuzluk yakınmaları olduğu, vardiyalı çalışmanın uyku kalitesini olumsuz etkilediği, mesai saati değişikliğinin uyku uyuyamama sorununa neden olduğu saptanmıştır (Ergüney ve ark, 2001; Zverev ve ark, 2009; Asi Karakaş, Gönültaş ve Okanlı, 2017). Bizim de çalışmamızda rol-aktivite dengesinde bozukluk arttıkça, yaşam kalitesini değerlendirmek için kullandığımız, Nottingham sağlık profili alt parametresi olan uyku parametresinde hafif etkilenim olduğu ortaya çıkmıştır. Yani vardiyalı çalışan kadın hemşirelerin, var olan çalışma saatlerinden dolayı uyku problemleri yaşadığını tespit etmiş bulunuyoruz.

Gece vardiyasında çalışan hemşireler üzerine Türk hemşireler derneğinin yaptığı bir çalışmada, normalden uzun süre ve çok sayıda hastaya bakım verme sorumluluğunu içeren koşullarda çalışmanın, fiziksel sağlıkları üzerine bir ya da birden fazla olumsuz etkisi olabildiği görülmüştür (THD, 2008). Bizim çalışmamızda da, vardiyalı çalışan hemşirelerde rol-aktivite dengesi bozuldukça, yaşam kalitesi için kullandığımız Nottingham sağlık profilindeki fiziksel aktivite alt parametresi hafif etkilenim tespit edilmiş olup, katılımcıların günlük rutinlerindeki hareketlerinde hafif zorluklar yaşadığı görülmüştür.

Vardiyalı çalışan kadın hemşirelerde rolaktivite dengesi ve yaşam kalitesi arasındaki ilişkinin incelenmesi ile ilgili daha önce bir çalışma yapılmadığı bilinmektedir. Bu konunun hemşirelerin serbest zaman, üretkenlik ve kendine bakım başlıklarında olmak üzere, tüm yaşamını etkilediğini gördüğümüz çalışmamızda en önemli kısıtılığımız örneklemimizi oluşturan grubun sadece Türkiye'nin üç ilinden oluşmuş olmasıdır. Ayrıca tam olarak çalışmanın bir kısıtlılığı olmasa da hemşireler açısından bu durumun genellenebilmesi için erkek hemşirelerin de incelenmesi uygun olacaktır.

Çalışmadan elde edilen bulgular doğrultusunda, yoğun ve zorlu bir çalışma hayatı olan vardiyalı çalışan kadın hemşirelerin, rolaktivite dengelerinin ankete göre orta düzeyin üzerinde bozuk olduğu, yaşam kalitelerinin ise orta düzeyin altında olumsuz etkilendiği görülmektedir. Bireyin fiziksel aktivite ve enerji düzeyi, uyku kalitesi, ağrı bulguları, ruhsal ve sosyal durumu gibi sağlığıyla ilişkili parametrelerin etkilenmiş olması, üzerinde durulması gereken önemli sorunlardır. Hemşirelerin rol-aktivite dengesinin düzenlenmesi, bütün bu sorunların üzerine odaklanılmasının gereğini ortaya koymuştur. Bu nedenle, rol-aktivite dengesi açısından vardiyalı çalışan kadın hemşirelerin değerlendirilmesinin rutin hale getirilmesi ve hemşirelerin sağlıkla ilişkili yaşam kalitelerini yükseltebilmeleri için vardiyalı çalışma sıklığının ve izin zamanlarının düzenlenmesi; serbest zaman, üretkenlik ve kendine bakım alanlarında anlamlı ve amaçı aktivitelerin oluşturulması gibi önlemlerin alınması değerli olacaktır. Hemşirelik gibi vardiyalı çalışan farklı meslek grupları için de durumun incelenmesi, sorunlara yönelik planlanan müdahale kapsamında rehabilitasyon programlarının oluşturulması ileri ki çalışmalar açısından ele alınması gereken konular arasındadır.

\section{Kaynaklar}

Anaby, D.R., Backman, C. L., \& Jarus, T. (2010). Measuring occupational balance: a theoretical exploration of two approaches. Can J Occup Ther, 77(5), 280-288. https://doi.org/10.2182/cjot.2010.77.5.4

Asi Karakaş, S., Gönültaş, N., \& Okanlı, A. (2017). Vardiyalı çalışan hemşirelerde uyku kalitesi. ERÜ Sağlık Bilimleri Fakültesi Dergisi, 4(1), 17-26. http://sbfedergi.erciyes.edu.tr/article/viewFile/5000152029/500018048 3

Christiansen, C. (1996). Three perspectives on balance in occupation. In R. Zemke \& F. Clark (Eds.), Occupational science: The evolving discipline (pp. 431-451). Philadelphia: F.A. Davis.

Cole, R.J., Loving, R.T., \& Kripke, D.F. (1990). Psychiatric aspects of shiftwork. Occup Med, 5(2), 301-314.

DeMoss, C., Mcgrail, M., Haus, E., Crain, L., \& Asche, S. (2004). Health and performance factors in health care shiftworkers. J Occup Environ Med, 46(12), 1278-1281.

Dür, M., Steiner, G., Fialka-Moser, V., Kautzky-Willer, A., Dejaco, C., Prodinger, B. \& et al (2014). Development of a new occupational balance-questionnaire: incorporating the perspectives of patients and healthy people in the design of a self-reported occupational balance outcome instrument. Health Qual Life Outcomes, 12,45.

Ergüney, S., Tan, M., Sivrikaya, S., \& Erdem, N. (2001). Hemşirelerin karşılaştıkları mesleki riskler. Atatürk Üniversitesi Hemşirelik Yüksekokulu Dergisi, 4(1), 63-73. http://e-

dergi.atauni.edu.tr/ataunihem/article/viewFile/1025000118/1 025000112

French, S.E., Lenton, R., Walters, V., \& Eyles, J. (2000). An empirical evaluation of an expanded Nursing Stress Scale. $J$ Nurs Meas, 8(2), 161-78.

Gedikli, F.G. (2008). Otomotiv sektöründe faaliyet gösteren bir işyerinde vardiya sistemi ile yapılan çalışmanın sağılk ve 
güvenlik üzerine etkileri. (Yüksek lisans tezi). Hacettepe Üniversitesi Sağlık Bilimleri Enstitüsü, Ankara.

International Labour Organization (ILO) (28. 04. 2016) Work place stress. Erişim adresi:https://www.ilo.org/wcmsp5/groups/public/ed_p rotect/protrav/safework/documents/publication/wcms_ 466547.pdf

Kaçmaz, N. (2011). Tükenmişlik (Burnout) sendromu. Journal of Istanbul Faculty of Medicine, 68(1), 29-32. http://dergipark.org.tr/iuitfd/issue/9260/116046

Küçükdeveci, A. A., McKenna, S.P., Kutlay, S., Gürsel, Y., Whalley, D., \& Arasil T. (2000). The development and psychometric assessment of the Turkish version of the Nottingham Health Profile. Int J Rehabil Res, 23(1), 3138.

Matuska, K. M., \& Christiansen, C. H., (2008). A proposed model of lifestyle balance. J Occup Sci, 15(1), 9-19. https://doi.org/10.1080/14427591.2008.9686602

Nicholson, P. J., \& D'Auriat, D. A. P. (1999). Shift work, health, the working time regulations and health assessments. Occup Med, 49(3), 127-137. https://doi.org/10.1093/occmed/49.3.127

Pati, A.K., Chandrawanshi, A., \& Reinberg, A. (2002). Shift work: consequence and management. Curr Sci, 81(1), 32-47. https://www.jstor.org/stable/24105001

Ruggiero, J.S. (2003). Correlates of fatique in critical care nurses. Res Nurs Health, 26(2), 434-444. https://doi.org/10.1002/nur.10106

Samaha, E., Lal, S., Samaha, N., \& Wyndham J.(2007). Psychological, lifestyle and coping contributors to chronic fatigue in shift-worker nurses. J Adv Nurs, 59(3), 221-232. https://doi.org/10.1111/j.13652648.2007.04338.x

Sarıcaoğlu, F., Akıncı, S. B., Gözaçan, A., Güner, B., Rezaki, M., \& Aypar, Ü. (2005) Gece ve gündüz vardiya çalışmasının bir grup anestezi asistanının dikkat ve anksiyete düzeyleri üzerine etkisi. Turk Psikiyatri Derg, 16(2), 106-112. http://www.turkpsikiyatri.com/C16S2/geceVe.pdf

Selvi, Y., Özdemir, P. G., Özdemir, O., Aydın, A., \& Beşiroğlu, L. (2010). Sağlık çalışanlarında vardiyalı çalışma sisteminin sebep olduğu genel ruhsal belirtiler ve yaşam kalitesi üzerine etkisi. Düşünen Adam Psikiyatri ve Nörolojik Bilimler Dergisi, 23(4), 238-243. https://doi.org/10.5350/DAJPN2010230403

Testa, M. A., \& Simonson, D. C. (1996). Assesment of quality-of-life outcomes. N Engl J Med, 334(13), 835840. https://doi.org/10.1056/NEJM199603283341306

Türk Hemşireler Derneği (2008, Aralık). 7 gün-24 saat / hasta başında Türkiye'de hemşirelerin çalışma koşulları. Ankara. Erişim tarihi 20 Haziran 2019, http://turkhemsirelerdernegi.org.tr/tr/yayinlar/thdyayinlari/brosurler-ve-raporlar/turkiyede-hemsirelerincalisma-kosullari.aspx

Ursavaş, A., \& Ege, E. (2004). Uyku apne sendromu ve trafik kazaları. Uludağ Üniversitesi Tıp Fakültesi Dergisi, 30(1), 3741. http://dergipark.org.tr/uutfd/issue/35253/391113

Wagman, P., Håkansson, C., \& Björklund A. (2012). Occupational balance as used in occupational therapy: A concept analysis. Scand J Occup Ther, 19(4), 322327. https://doi.org/10.3109/11038128.2011.596219

Wilson, J. (2002) The Impacts of shift patterns on healthcare professionals. J Nurs Manag, 10, 211-219. https://doi.org/10.1046/j.1365-2834.2002.00308.x

Yeşilçicek Çalık., K, Aktaş, S. , Kobya Bulut, H., \& Özdaş Anahar, E. (2015). Vardiyalı ve nöbet sistemi şeklindeki çalışma düzeninin hemşireler üzerine etkisi. Sağlık Bilimleri ve Meslekleri Dergisi, 2(1), 33-45. https://doi.org/10.17681/hsp.31345

Yıldırım, A., \& Hacıhasanoğlu, R. (2011). Sağlık çalışanlarında yaşam kalitesi ve etkileyen değişkenler. J Psychiatr Nurs, 2(2), 6168.

https://www.journalagent.com/phd/pdfs/PHD_2_2_61_68.pd $f$

Zverev, Y. P., \& Misiri, H.E. (2009). Perceived effects of rotating shiftwork on nurses' sleep quality and duration. Malawi Med J, 21(1), 19-21. http://dx.doi.org/10.4314/mmj.v21i1.10984 